\title{
An Internet-Based Multi-Approach Intervention Targeting University Students Suffering from Psychological Problems: Design, Implementation, and Evaluation
}

\author{
Marlene De Fabritiis ${ }^{1,+}$, Federica Trisolini ${ }^{1,+}{ }^{+}$, Gloria Bertuletti ${ }^{1}$, Ionut Daniel Fagadau ${ }^{2}$, Davide Ginelli ${ }^{2}{ }^{\mathbb{D}}$, \\ Katiuscia Pia Lalopa ${ }^{1}$, Lisa Peverelli ${ }^{1}$, Alessia Pirola ${ }^{1}$, Gaia Sala 1, Marta Maisto ${ }^{1}$, Fabio Madeddu 1,3, \\ Jorge Lopez-Castroman ${ }^{4,5,6}$, Daniele Romano ${ }^{1}\left(\mathbb{D}\right.$, Alessandro Gabbiadini ${ }^{1}\left(\mathbb{D}\right.$, Emanuele Preti ${ }^{1,3}$, \\ Daniela Micucci $^{2}$ (D) and Raffaella Calati $1,3,4, *$ (D)
}

check for

updates

Citation: De Fabritiis, M.; Trisolini, F.; Bertuletti, G.; Fagadau, I.D.; Ginelli, D.; Lalopa, K.P.; Peverelli, L.; Pirola

A.; Sala, G.; Maisto, M.; et al. An Internet-Based Multi-Approach Intervention Targeting University Students Suffering from Psychological Problems: Design, Implementation, and Evaluation. Int J. Environ. Res. Public Health 2022, 19, 2711. https://doi.org/10.3390/ ijerph19052711

Academic Editors: Regina Lee, Michael Brown, Wai Tong Chien and Sally Chan

Received: 30 December 2021 Accepted: 17 February 2022 Published: 25 February 2022

Publisher's Note: MDPI stays neutral with regard to jurisdictional claims in published maps and institutional affiliations.

Copyright: (c) 2022 by the authors. Licensee MDPI, Basel, Switzerland. This article is an open access article distributed under the terms and conditions of the Creative Commons Attribution (CC BY) license (https:// creativecommons.org/licenses/by/ $4.0 /$ )
1 Department of Psychology, University of Milano-Bicocca, 20126 Milan, Italy; m.defabritiis@campus.unimib.it (M.D.F.); f.trisolini@campus.unimib.it (F.T.); g.bertuletti1@campus.unimib.it (G.B.); k.lalopa@campus.unimib.it (K.P.L.); 1.peverelli2@campus.unimib.it (L.P.); a.pirola14@campus.unimib.it (A.P.); g.sala50@campus.unimib.it (G.S.); m.maisto2@campus.unimib.it (M.M.); fabio.madeddu@unimib.it (F.M.); daniele.romano@unimib.it (D.R.); alessandro.gabbiadini@unimib.it (A.G.); emanuele.preti@unimib.it (E.P.)

2 Department of Informatics, Systems and Communication (DISCo), University of Milano-Bicocca, 20126 Milan, Italy; i.fagadau@campus.unimib.it (I.D.F.); davide.ginelli@unimib.it (D.G.); daniela.micucci@unimib.it (D.M.)

3 BICAPP-Bicocca Center for Applied Psychology, University of Milano-Bicocca, 20126 Milan, Italy

4 Department of Adult Psychiatry, Nîmes, University Hospital, 30900 Nîmes, France; jorge.lopezcastroman@chu-nimes.fr

5 IGF, CNRS-INSERM, Université Montpellier, 34094 Montpellier, France

6 CIBERSAM, 28029 Madrid, Spain

* Correspondence: raffaella.calati@unimib.it

$\dagger$ These authors contributed equally to this work.

\begin{abstract}
Despite the widespread prevalence of mental health problems, most psychological distress remains untreated. Internet-based psychological interventions can be an essential tool for increasing treatment availability and accessibility. The main objective of the MindBlooming project is to design and implement an innovative Internet-based multi-approach treatment for university students suffering from psychological or physical problems. The intervention will focus on symptoms of depression, anxiety, sleep problems, self-destructive thoughts, job- and study-related stress and burnout, and chronic pain. It will be based on different approaches, primarily psychoeducation, Cognitive-Behavioral Treatment (CBT), and third-wave CBT. At the end of the treatment, user satisfaction and usability will be assessed. In addition, two further aims will be evaluating the treatment efficacy through a randomized controlled trial and tuning a predictive model through Machine Learning techniques. The intervention consists of a 7-week treatment on two problematic areas according to each students' personal needs, identified through an initial assessment. Besides the treatment assigned following the initial screening, participants will also be assigned to a different module to improve their relational skills. The treatment, which can be accessed through a mobile app, consists of psychoeducational videos followed by related exercises. We expect MindBlooming to be a remarkable tool for promoting the mental health of university students.
\end{abstract}

Keywords: internet-based intervention; cognitive-behavioral treatment; university students; randomized controlled trial

\section{Introduction}

Worldwide, data about the prevalence of mental health issues are alarming: in 2020, during the COVID-19 pandemic, more than $30 \%$ of the general population suffered from depression, anxiety, distress, or insomnia [1]. University students appeared to be highly 
vulnerable to the risk of mental health deterioration during this period [2]. Specifically, in Italy, between 2019 and 2021, 14\% of university students had at least one mental disorder [1]. Young adulthood is a critical phase during which the first psychological symptoms may appear, triggered by the stress related to the university studies and to the new responsibilities of adulthood [2,3]. The prevalence of psychological issues among university students, including depression, anxiety [4], insomnia [5], suicidal thoughts and behaviors [6], stress or burnout [7], and chronic pain [8], appears to be increasing worldwide [5,9]. Mental wellbeing is connected to our emotionality [10], which is why social isolation and loneliness have a substantial impact on mental health outcomes [11,12] and emotional regulation difficulties represent a risk factor for mental disorders [13]. Furthermore, psychological distress in university students is often associated with a higher risk of failure and dropout from the course of studies [14].

Despite the psychological problems' high prevalence and significant negative consequences (linked to disability, severe socio-economic issues, and even death), only a minority of university students can access proper treatment [15]. Consequently, promoting university students' well-being should be a priority of the educational and social systems [16].

Internet-based interventions (IBIs) are a promising way to improve treatment accessibility and availability [17]. These entail the technological implementation of therapeutic treatments that occur in different ways: through web-based platforms, via mobile applications, virtual reality, video games, or feedback and reinforcement interventions through notifications and nudges [15]. IBIs overcome numerous limitations of more traditional forms of treatment related to costs, waiting lists, time and space limits, and the stigma associated with psychotherapy [18]. Several studies reported the effectiveness of self-help IBIs for different issues (i.e., depression, anxiety, sleep-related problems, and chronic pain) compared to control groups [15]. Comparable effectiveness to traditional face-to-face treatments has been observed $[19,20]$. To date, no risks or negative effects of IBIs have been highlighted [21]. IBIs appear to be a promising tool for university students because, among them, the use of the Internet and smartphones is widespread [22].

MindBlooming is a mobile app for a multi-approach treatment of psychological and physical problems in university students. It represents an attempt to respond to the growing psychological distress of the university population through an easily accessible and always available treatment. The name "MindBlooming" was chosen to evoke the idea of "mental growth", framing one's mind as a plant that needs to be cared for. Similar studies have already been performed worldwide [23-26] but most of them are based on a single intervention approach and face only one or two mental problems. MindBlooming offers a multi-approach and transdiagnostic treatment that allows users to work on different issues through the same app, reducing the commitment needed to use various applications for comorbid issues and therefore increasing treatment efficacy [27]. To the best of our knowledge, this will be the first attempt to deliver such an intervention (i.e., a multiapproach IBI that deals with different psychological and physical problems, and is tailored) to the university students' population.

\section{Aims and Hypotheses}

MindBlooming is a two-year research project with multiple primary goals and related hypotheses. Firstly, we aim to design and implement a new Internet-Based Multi-Approach Intervention (IB-MAI) for university students. The intervention covers a wide range of mental health issues that are relevant within the university student population $[11,28]$ and that are treatable with IBIs [23,25,29]. Furthermore, the intervention is tailored to the individual's needs. The mental health issues that MindBlooming addresses are depression, anxiety, sleep problems, self-disruptive thoughts, job- and study-related stress and burnout, and chronic pain.

Secondary aims will be: (1) the feasibility assessment of this IB-MAI (in terms of acceptability, satisfaction, usability, and uptake) through a pilot study on a restricted sample; (2) a randomized controlled trial (RCT) to compare the IB-MAI with web-education, as 
the control condition (CC); and (3) exploratory analysis to tune a predictive model on the collected data adopting Machine Learning techniques.

We hypothesize that: (1) the design and implementation of the IB-MAI treatment will be feasible; (2) the majority of the students will accept and be satisfied with the treatment; (3) the IB-MAI will be superior to the CC on both the primary and secondary outcome measures; and (4) the large amount of collected data will allow the identification of predictors of treatment response and different trajectories in treatment response.

\section{Materials and Methods}

The project has already been approved by the Internal Review Board (IRB) of the University of Milan-Bicocca at the beginning of the year 2021 (protocol number: 0018862/21; date: 16 February 2021). The study will be organized into two phases. The first phase, which has already been completed, focuses on the IB-MAI design and implementation. An in-depth analysis of current IBIs was conducted to design the IB-MAI. This allowed us to analyze the strengths and limitations of different approaches and use these observations to guide the development of the intervention. Our IB-MAI was designed as a mobile app for both Android and iOS to increase the number of potential users. MindBlooming provides a set of psychoeducational videos (with transcripts) about the psychological issues faced during treatment, as well as questionnaires and exercises to collect information before, during, and after the treatment itself. We followed the design principle of Material Design [30], which is a system of guidelines, components, and tools that support the best practices of user interface design and specify theories and practical applications of the interaction among human and machine for mobile development. The user interface (Figure 1) has been developed following the current usability standards, and it comprises features such as reminders, nudges, a calendar, and a diary.
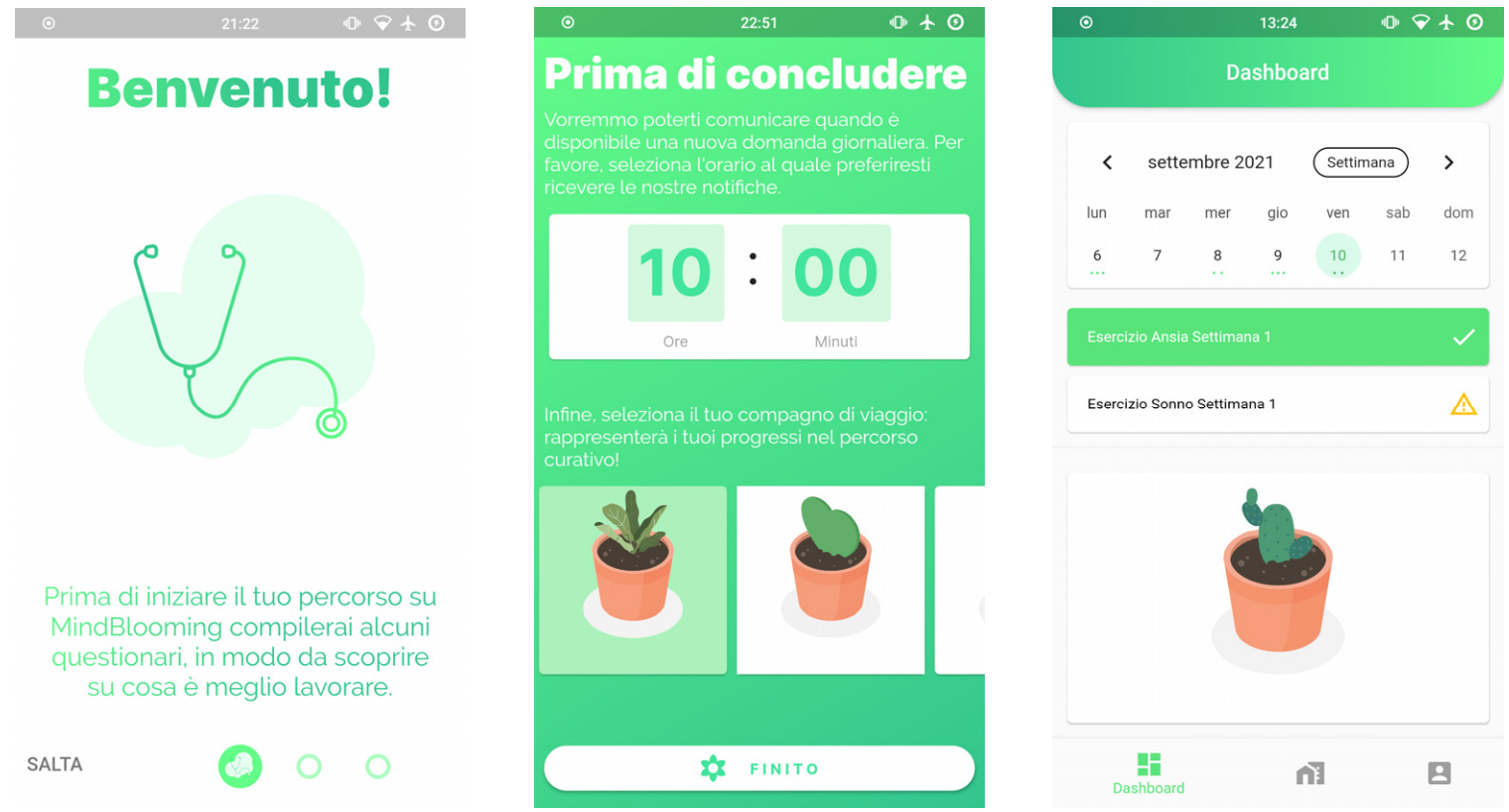

Figure 1. MindBlooming app user interface.

The second phase will consist of 3 main steps. In the first step, a pilot study will be performed by recruiting 30 participants to evaluate the feasibility of this IB-MAI (acceptability and satisfaction, usability, and uptake). An RCT will be conducted in the second step. The pilot study and the RCT structure will be described in detail in the following paragraphs. Lastly, data analysis will be performed through Machine Learning techniques. 


\subsection{Participants and Recruitment}

University students aged between 18 and 29 will be invited to participate; to be included, they must declare to have experienced at least mild- or moderate-intensity forms of mental health symptoms (no specific diagnostic screening will be performed in this phase), and they must not currently be in psychotherapy or start psychotherapy during the entire duration of the treatment. Participants are also required to have a phone based on Android or iOS operating systems and an Internet connection. Exclusion criteria include the inability to communicate in Italian.

Participants will be recruited through social networks (e.g., Facebook and Instagram), students' WhatsApp groups (to include students not using the mentioned social networks, thus avoiding selection biases), and the Sona System recruitment platform made available by the University of Milan-Bicocca. Moreover, to further encourage participation, posters will be placed in local universities. In this phase they will receive preliminary information. Then, through a web link, they will be redirected to a specific landing page with more detailed information about the mobile app. On this web page, participants will be redirected to the proper marketplace (Apple Store and Google Play) to download the app on their smartphones. If possible, European Credit Transfer and Accumulation System (ECTS) credits will be awarded to participants. Once their eligibility has been verified and they have signed an online informed consent form, students interested in participating will be included in the study. We will collect the information concerning the diverse participants' recruitment channels to ensure that there is no difference in baseline data among different recruitment channels. The same standards for data collection will be applied through different channels.

\subsection{Pilot Study Design}

For the pilot study, 30 participants will be recruited to evaluate the feasibility (in terms of acceptability and satisfaction, usability, and uptake) of the IB-CBT program. Inclusion and exclusion criteria, detailed in the following paragraphs, will be the same as for the RCT. Baseline and post-treatment assessments will be conducted using the same methods and scales used in the RCT and described in the following paragraphs. We assume most students will accept the treatment and be satisfied with it. However, some participants may run into technical or access issues, as stated by previous studies [28] (e.g., Wilks et al., 2018).

Feasibility Measures

At the end of the pilot, different feasibility aspects will be assessed using the following scales:

* Treatment satisfaction, measured by a modified version of the Client Satisfaction Questionnaire (CSQ-8) [31], an 8-item questionnaire rated on a 4-point Likert scale; and a Visual Analogue Scale (VAS) [32];

* System usability, via completion of a modified version of the System Usability Scale (SUS) [33], which is a 10-item questionnaire rated on a 5-point Likert scale that provides a global measure of subjective usability; and a VAS [32];

* Adherence rates for each lesson and the overall program.

\subsection{RCT Design}

This study will be conducted in accordance with the Consolidated Standards Of Reporting Trials (CONSORT) checklist for the RCT design [34]. Participants will be randomly assigned following blind simple randomization procedures when they complete the baseline assessment (randomization sequence under computer control adopting computerized random numbers) to 1 of 2 treatment groups (see Figures S1 and S2 for the study design and assessments). We only keep the 1:1 ratio constraint at the 260 th participant, meaning that when one group reaches 130 participants, all the remaining volunteers (up to the total of 260) will be allocated to the other group. Students will be randomized to IB-MAI or CC. Participants in the intervention condition will receive an 8-week unguided IB-MAI 
program, i.e. MindBlooming. Participants in the CC condition will access websites with information about their specific areas of distress identified at baseline. Participants will be assessed with repeated measures (baseline, 8 weeks, 12 weeks, and 24 weeks). The RCT participants' flow is presented in Figure 2.

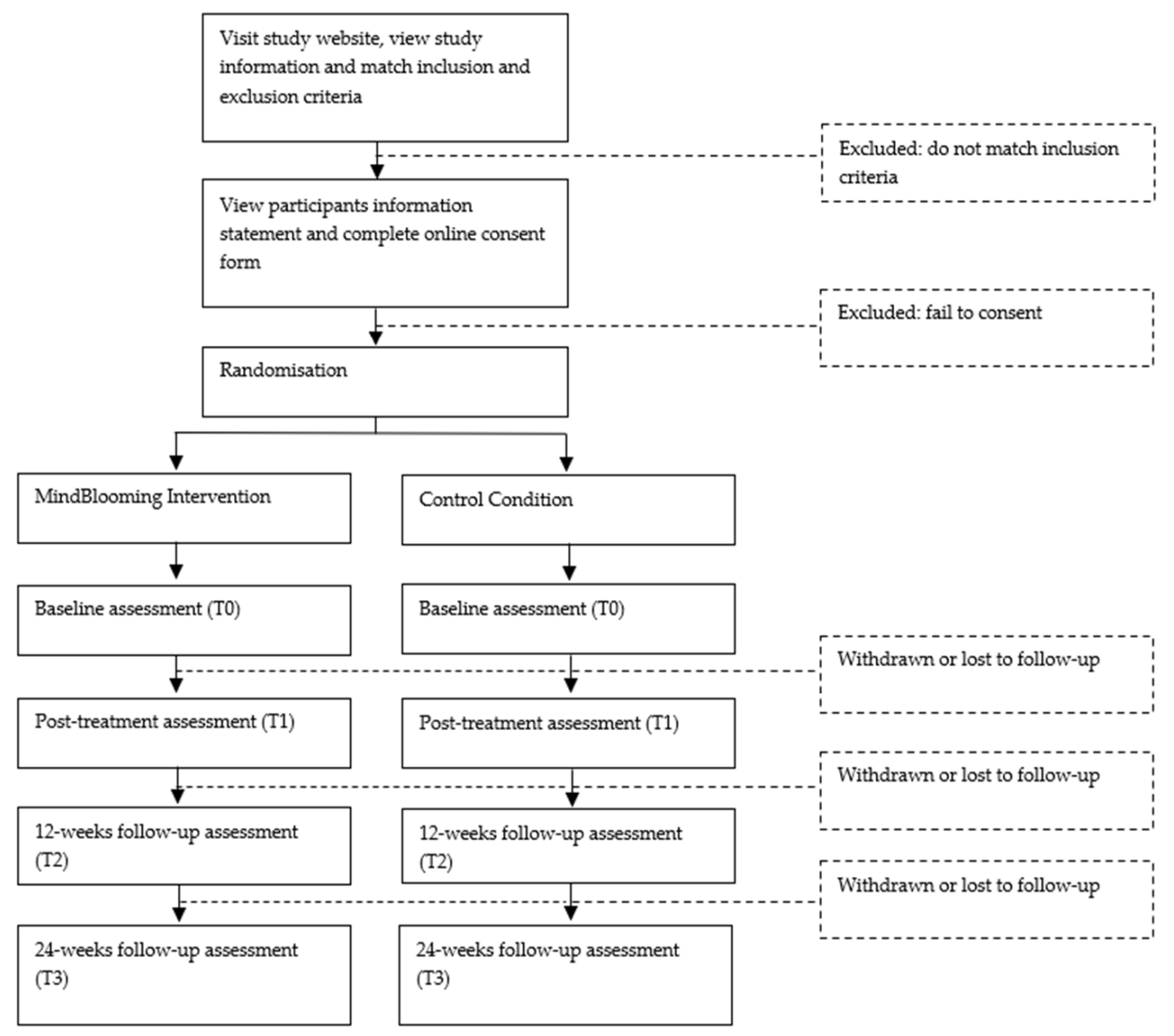

Figure 2. RCT's participants' flow.

\subsection{Intervention}

MindBlooming is conceived as an Internet-Based Multi-Approach Intervention (IBMAI) intended to provide psychoeducation and teach new strategies to cope with different psychological problems. We consider MindBlooming to be multi-approach since it integrates different psychotherapeutic strategies such as Cognitive Behavioral Therapy [35], Acceptance and Commitment Therapy [36], Mindfulness-Based Cognitive Therapy (MBCT) [37,38], Mindfulness-Based Stress Reduction (MBSR) [39], and Dialectical Behavioral Therapy [40]. All these interventions are evidence-based and several studies proved their efficacy in treating different psychological conditions (for an overview, see [41] and APA division 12 list of research-supported psychological treatments, https: / / div12.org/psychological-treatments / , accessed date 29 December 2021). The intervention consists of 6 interactive modules: depression, anxiety, sleep problems, self-disruptive thoughts, job- and study-related stress and burnout, and chronic pain. A total of two modules will be assigned to each participant based on the initial screening and specific requests and preferences. In addition to the assigned treatments based on the initial screening, all participants will receive a separate training to improve their relational and empathy skills: during the 6th week, they will have access to two videos focused on the importance of relationships on our health, social support as a protective factor, social isolation and loneli- 
ness as a risk factor, emotion regulation, and empathy. Afterward, they will have access to a set of exercises, including quizzes about social relationships, assertive communication training, DBT [40], and Interpersonal Psychotherapy (IPT) for Depression strategies (which correlate depressive symptomatology to relational problems) [42]. Moreover, during the 7 th week of treatment, more contents in the same formats (videos, texts, and quizzes) will be proposed, focusing on emotions and relationships problems related to the specific issues faced in the assigned modules (e.g., problems in relationships in association with depressive symptoms).

Every week for the entire duration of the intervention, participants will have access to one session per module, except for the 6th week, which is dedicated to the treatment of relational problems: regardless of the specific issue (depression or anxiety, etc.), this training deals with relational issues relevant to everyone, hence the importance of transversally proposing it. The modules will be presented as follows:

1st week: module 1 and 2 sessions;

2nd week: module 1 and 2 sessions;

3rd week: module 1 and 2 sessions;

4th week: module 1 and 2 sessions;

5th week: module 1 and 2 sessions;

6th week: relational problems related to difficulties in emotion regulation and empathy deficits session;

7th week: module 1 and 2 sessions about relapse prevention, future planning by reflecting on how to attain goals and implement behavioral changes, orientation, and conclusion.

All online sessions will include psychoeducational videos (brief seminars of 15 min each, with audios and PowerPoint presentations), about epidemiology, explanatory models, risk and protection factors, treatments, and some specific aspects of each psychological issue. Once the videos have been seen, training exercises will be proposed to help participants to integrate the content of the sessions into their daily lives (Figure 3). Contents and approaches used for each module are further presented in Table 1.
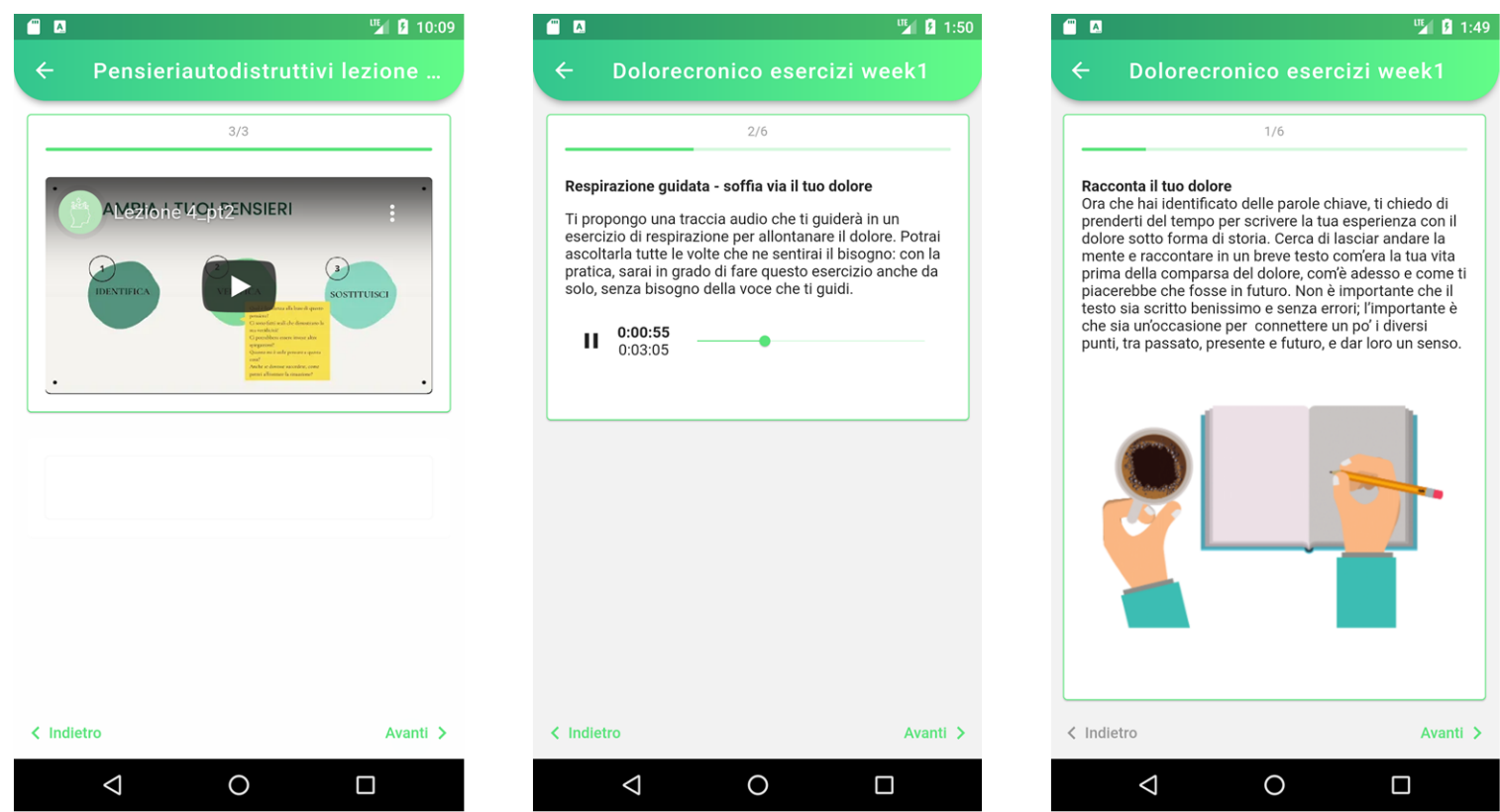

Figure 3. Screenshot of an example of psychoeducational video and exercises. 
Table 1. Contents and approaches of each module.

\begin{tabular}{|c|c|c|c|c|c|}
\hline Module & & Psychoeducation & Exercises & & Approaches \\
\hline Depression & $\begin{array}{l}(1) \\
(2) \\
(3) \\
(4) \\
(5) \\
(6)\end{array}$ & $\begin{array}{l}\text { The definition of depression } \\
\text { and its epidemiology; } \\
\text { Two psychological models } \\
\text { of depression; } \\
\text { Recognizing and } \\
\text { challenging unhelpful } \\
\text { thoughts, emotions, } \\
\text { and behaviors; } \\
\text { Learning problem- } \\
\text { solving strategies; } \\
\text { Improving levels of } \\
\text { motivation and self-esteem; } \\
\text { Preventing and } \\
\text { managing relapses. }\end{array}$ & $\begin{array}{ll}\text { - } & \text { Thoughts challenging; } \\
\text { - } & \text { Problem-solving; } \\
\text { - } & \text { Shifting attention; } \\
\text { - } & \text { Behavioral activation; } \\
\text { - } & \text { Relaxation and } \\
\text { - } & \text { breathing strategies; } \\
\text { Mindfulness techniques. }\end{array}$ & $\nLeftarrow$ & $\begin{array}{l}\text { Cognitive Behavioral } \\
\text { Therapy }[35,43]\end{array}$ \\
\hline Anxiety & $\begin{array}{l}(2) \\
(3) \\
(4) \\
\text { (5) } \\
\text { (6) }\end{array}$ & $\begin{array}{l}\text { Definition of anxiety, its } \\
\text { epidemiology, and } \\
\text { major causes; } \\
\text { Psychological models of } \\
\text { anxiety and useful strategies } \\
\text { for its management; } \\
\text { Definition of a particular } \\
\text { type of anxiety disorder: } \\
\text { panic disorder; } \\
\text { Problems related to anxiety, } \\
\text { its components, reduction of } \\
\text { avoidance, and } \\
\text { safety behaviors; } \\
\text { Emotions, behavior, and } \\
\text { mindfulness techniques; } \\
\text { Preventing and } \\
\text { managing relapses. }\end{array}$ & $\begin{array}{l}\text { - } \quad \text { Thoughts challenging; } \\
\text { - } \quad \text { Problem-solving; } \\
\text { - } \quad \text { Shifting attention; } \\
\text { - } \quad \text { Behavioral activation; } \\
\text { - } \quad \text { Relaxation and } \\
\text { breathing strategies; } \\
\text { - } \quad \text { Mindfulness techniques. }\end{array}$ & $\nLeftarrow$ & $\begin{array}{l}\text { Cognitive-Behavioral } \\
\text { Therapy for Anxiety } \\
\text { Disorders }[43,44] \text {; } \\
\text { Acceptance and } \\
\text { Commitment Therapy } \\
(\mathrm{ACT})[36]\end{array}$ \\
\hline Sleep problems & $\begin{array}{l}(2) \\
(3) \\
(4) \\
(5) \\
(6)\end{array}$ & $\begin{array}{l}\text { Defining the architecture of } \\
\text { normal sleep and its role in } \\
\text { daily functioning; } \\
\text { The insomnia problem; } \\
\text { Cognitive techniques of the } \\
\text { Cognitive Behavioral } \\
\text { Therapy for Insomnia; } \\
\text { Behavioral aspects of } \\
\text { Cognitive Behavioral } \\
\text { Therapy for Insomnia; } \\
\text { Identifying the other } \\
\text { sleep disorders; } \\
\text { Maintenance strategies and } \\
\text { relapse prevention. }\end{array}$ & $\begin{array}{l}\text { - } \quad \text { Sleep restriction; } \\
\text { Breathe and } \\
\text { - } \quad \text { relaxation exercises; } \\
\text { Progressive } \\
\text { muscles relaxation; } \\
\text { - } \quad \text { Restriction of time in bed; } \\
\text { - } \quad \text { Thognitive restructuring; } \\
\text { and challenging. }\end{array}$ & $\nLeftarrow$ & $\begin{array}{l}\text { Cognitive-Behavioral } \\
\text { Therapy for Insomnia } \\
\text { (CBT-I) [45-48]; } \\
\text { Progressive muscle } \\
\text { relaxation }[49,50]\end{array}$ \\
\hline
\end{tabular}


Table 1. Cont.

\begin{tabular}{|c|c|c|c|c|c|}
\hline Module & & Psychoeducation & Exercises & & Approaches \\
\hline Self-disruptive thoughts & $\begin{array}{l}\text { (3) } \\
(4) \\
(5) \\
(6)\end{array}$ & $\begin{array}{l}\text { Definition of self-disruptive } \\
\text { thoughts and epidemiology; } \\
\text { Psychological models of } \\
\text { self-disruptive thoughts and } \\
\text { psychotherapeutic strategies; } \\
\text { Identifying and challenging } \\
\text { negative thoughts; } \\
\text { Creating a weekly } \\
\text { action plan; } \\
\text { Structuring the } \\
\text { problem solving; } \\
\text { Maintenance strategies and } \\
\text { relapse prevention. }\end{array}$ & $\begin{array}{ll}\text { - } & \text { Security plan; } \\
\text { - } & \text { Identifying life reasons; } \\
\text { - } & \text { Building a weekly plan of } \\
& \text { well-being; } \\
\text { - } & \text { Relaxation strategies; } \\
\text { - } & \text { Thoughts challenging; } \\
\text { - } & \text { Behavioral activation; } \\
\text { - } & \text { Problem-solving. }\end{array}$ & 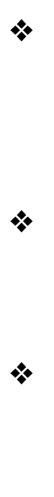 & $\begin{array}{l}\text { Brief } \\
\text { Cognitive-Behavioral } \\
\text { Therapy for Suicide } \\
\text { Prevention } \\
\text { (BCBT) [51]; } \\
\text { Cognitive Behavioral } \\
\text { Therapy for Suicide } \\
\text { Prevention } \\
\text { (CBT-SP) [52-54]; } \\
\text { Dialectical Behavior } \\
\text { Therapy } \\
\text { (DBT) [40,54,55] }\end{array}$ \\
\hline
\end{tabular}

(1) Definition of stress and burnout, work context, and epidemiology;

(2) Stress and burnout in university students and burnout explanatory models;

Job- and study-related stress and burnout

(3) Risk and protective factors and treatment;

(4) Coping strategies, resilience, and the importance of emotions;

(5) Errors of thought and perfectionism, and procrastination;

(6) Recap and maintenance of strategies.
(1) Definition of chronic pain and epidemiology;

(2) Psychological models of chronic pain, useful strategies for its management, and goal setting;

Chronic pain

(3) Challenging unhelpful thoughts and pain acceptance;

(4) Coping strategies and pacing;

(5) Emotions and assertive communication

(6) Preventing and managing relapses.
- Meditation audios;

- Relaxational training;

- Mindfulness exercises;

- Progressive muscular relaxation.
* Mindfulness-Based Stress Reduction (MBSR) [39];

- Reduction Progressive relaxation [49]

Quizzes will be presented during each session, along with the possibility for the participants to reply and insert text. Subsequent sessions will be available only if the previous session, and a minimum of related exercises, is completed within 7 days ( +3 days to be flexible in the case of students unable to maintain the pace). Even if the contents are completed before the 7 th day from the start, new contents will be available from the 7 th day onwards. When a new week of treatment is available, participants have 3 days to start 
completing the tasks. If the subjects do not respect the deadlines, they will be excluded from the study. Participants also have access to a list of available supplementary resources.

For the entire duration of the treatment, participants must answer daily and weekly questions related to each of the two treatment modules they are individually following to constantly monitor the progress of some key variables. The sixth week is an exception, as daily and weekly questions will also address relational issues. Answers are saved and shown to participants on a calendar to follow-up changes over time. Moreover, participants are informed that they can contact an e-Coach for technical questions and concerns or emotional crisis at any time during the intervention.

\subsection{Control Condition}

For each participant, the CC consists of indications to websites specifically focused on the different psychological conditions (depression, anxiety, sleep problems, self-disruptive thoughts, job- and study-related stress and burnout, and chronic pain) they report as areas of distress according to the global screening.

\subsection{Outcome Measures}

Participants will be screened with a complete online battery to assess their symptoms, including both primary and secondary outcome measures, at pretreatment baseline (T0), after the 7-week IB-MAI treatment, or CC completion (T1), at 12-week follow-up (T2), and 24-week follow-up (T3) (see Figures S1 and S2 for the study design and assessments). Moreover, at pretreatment time (T0), socio-demographic questions are included; these concern marital status, educational qualification, employment status, physical or psychiatric illnesses, and past or current therapies. Questions related to gender and the COVID-19 pandemic are included to investigate the influence of the pandemic on students' mental health status. These items were drawn up according to the International COVID-19 Suicide Prevention Research Collaboration guidelines [56]. In contrast, those relating to gender were taken from the Williams Institute of the UCLA School of Law for health surveys [57].

Since participants have a timeframe to begin and complete each week of treatment, the overall treatment duration can differ among subjects. Therefore, post-treatment and follow-up time points will be calculated for each participant, starting from the end of the last activity.

\subsubsection{Primary Outcome Measures}

* Beck Depression Inventory (BDI-II) [58,59], composed of 21 items investigating depressive symptoms (see Supplementary File S1 for a thorough description of the scales).

* State-Trait Anxiety Inventory (STAI) [60,61], consisting of 40 items exploring state and trait anxiety.

* Italian Version of the Pittsburgh Sleep Quality Index (PSQI) [62,63], consisting of 19 items to investigate sleep quality in the last month.

* Brief version of the Columbia-Suicide Severity Rating Scale (C-SSRS) [64] modified, consisting of 4 items investigating current suicide risk and 5 items investigating lifetime risk.

* School Burnout Inventory (SBI) [65,66], composed of 9 items exploring three dimensions of burnout, i.e., exhaustion, cynicism, and sense of inadequacy.

* Difficulties in Emotion Regulation Scale (DERS-20) [67,68] consisting of 20 items investigating emotional regulation skills, and the Brief Interpersonal Reactivity Index (B-IRI) [69,70], consisting of 16 items investigating empathic response skills.

* Brief Pain Inventory (BPI) [71,72], composed of 15 items measuring the intensity of pain and its impact on daily functioning.

* World Health Organization Quality of Life-short version (WHOQOL-BREF) [73], consisting of 26 items investigating the quality of life. 


\subsubsection{Secondary Outcome Measures}

* Visual Analogue Scales (VAS) for psychological and physical pain (6 items) [32].

* Insomnia Severity Index (ISI) to investigate the impact of insomnia in the last two weeks (7 items) [74].

* Toronto Alexithymia Scale (TAS-20), consisting of 20 items investigating levels of alexithymia $[75,76]$.

* Coping Orientation to the Problems Experienced (COPE-NVI-25) [77,78], consisting of 25 items investigating coping strategies.

* Life Events Checklist (LEC) [79], composed of 16 items investigating the subject's stressful experiences.

* Reasons for Living Inventory (RFLI) [80], consisting of 48 items investigating the subject's reasons for living.

* COVID-19-related questions compiled according to the International Association for Suicide Prevention (IASP) guidelines for suicide prevention research [56].

Given the feasibility nature of this study, data on the program's acceptability will also be collected at post-treatment (T1) through the same measures used in the pilot study and described in the related paragraph.

\subsection{Sample Size Calculation}

Considering the attrition rate, we will recruit 260 students to obtain 200 study completers. A total of two-hundred participants will allow to detect an effect size of at least $\mathrm{d}=0.40$, fixing a power $(1-\beta)$ of $80 \%$, and an alpha of 0.05 (two-tailed) in a between group comparison (e.g., comparing the two treatments). This sample size is similar to Harrer et al. [25]. The effect size is estimated considering a recent meta-analytic review for Internet-based stress interventions which reports effect sizes ranging between $d=0.32$ and $\mathrm{d}=0.64$ [81].

Frequentist and Bayesian approaches have their own advantages and drawbacks in data analysis. We will adopt both to provide robust evidence to the specific statistical approach.

We conducted a Bayes Factor Design Analysis (BFDA) [82] (i.e., the counterpart of power analysis in the Bayesian world) to estimate the Bayesian analysis sensitivity, given the sample size of 200 people. We simulated 10,000 results, fixing the Bayes Factor (BF) decision boundary at 10 , and an estimated effect size for a true $\mathrm{H} 1$ equal to $\mathrm{d}=0.40$. The BFDA simulation was performed for a default prior (i.e., a Cauchy distribution with a scale $=0.707$ ) and an informative prior (i.e., a t distribution with $\mu=0.35, \mathrm{df}=3, \mathrm{r}=0.102$ ), considering true $\mathrm{H} 0$ (i.e., $\mathrm{d}=0)$ and $\mathrm{H} 1(\mathrm{~d}=0.40)$. Given those parameters, we estimate to surpass the decision boundary for $\mathrm{H} 1$ in $87.8 \%$ adopting the default prior and $93.8 \%$ of the case adopting the informed prior. In the case of a true $\mathrm{H} 0$, the decision boundary is surpassed in $45.5 \%$ and $62.2 \%$ of the cases adopting the default or the informed prior, respectively. The design is robust to the misleading evidence, showing a false positive evidence rate of 0.002 and 0.006 adopting the default or the informed prior. No false negative evidence has been observed over 10,000 simulations with any of the two priors. In the case of inconclusive evidence, we will increase the sample size until the BF decision boundary is surpassed ( $\mathrm{BF}>10$ ) in either one of the two directions supporting H1 or H0.

We expect to have enough data to tune a model that highlights treatment response predictors and different trajectories in students' response to treatment. We will test five different algorithms: Linear Discriminant Analysis (LDA); Classification and Regression Trees (CART); k-Nearest Neighbors (kNN); Support Vector Machines (SVM) with a linear kernel; and Random Forest (RF). This will offer a good mixture of simple linear (LDA), non-linear (CART, kNN), and complex non-linear methods (SVM, RF).

\subsection{Statistical Methods}

Statistical analyses will be conducted adopting both a frequentist and a Bayesian approach to provide robust evidence favoring or against the intervention. 
The main study outcome is to verify the effectiveness of the intervention: this would be verified by a T0 to T1 delta different from 0 . Additionally, we will test the effectiveness of the IB-MAI against the CC group comparing the two T0 to T1 deltas. We will use a series of $t$-tests and its Bayesian [83] corresponding test.

Stability over time will be verified with a mixed ANOVA using the T1, T2 and T3 datapoints as within-subject measures and group (IB-MAI versus CC) as a between-subjects factor. We will use "classic" (i.e., frequentist) ANOVA and its corresponding Bayesian version [84] for each primary and secondary outcome measure.

For what concerns the predictive model, we will explore the possibility to use ML algorithms to tune a model able to predict the responders on each of the primary outcomes starting from the socio-demographic information collected and the primary and secondary outcome measures in two steps. First, we will use only socio-demographic information to predict the primary outcome measure of each module. Second, we will use the sociodemographic information, the other primary, and all the secondary outcome measures to predict the primary outcome of each specific module. Before entering an outcome measure as a target variable (i.e., to be classified/predicted variable), variables have to be dichotomized. We will classify participants as responders or non-responders, adopting the minimum clinical importance difference and adopting a distribution approach [85]. A responder will be defined as a participant that records a change larger than 1 standard error of the mean (SEM) calculated on the baseline distribution. For example, the effectiveness of the first module is measured primarily on the BDI-II scale. We will first identify participants that change more than 1 SEM to classify responders and non-responders. Then we will use ML algorithms to predict this outcome starting from socio-demographic in a first step, and socio demographic plus the other outcome variables (except BDI-II of course) in a second step. We will test five different algorithms to have a good mixture of simple linear (LDA), nonlinear (CART, kNN), and complex nonlinear (SVM, RF) methods, thus covering the most used and diffused ML methods [86]. A total of $20 \%$ of the data will be held out for testing purposes, thus ML training will be performed on the remaining $80 \%$ data of the total sample. The portion of sample holdout will be set at the beginning and kept constant for all the algorithms tested and outcomes targeted, to make the different models' performances directly comparable.

\section{Discussion}

This paper describes MindBlooming, a new IB-MAI designed to promote mental health in university students, and describes the study protocol, testing its efficacy through a pilot study and a two-arm RCT. The treatment will be compared to a control condition. Participants' acceptance and usability of the app will also be assessed to identify possible implementation barriers.

A primary limitation of our project might be represented by the treatment dropout level; due to its overall structure and duration, an IB-I such as MindBlooming requires user commitment and the investment of time and resources, which are not always available. Moreover, some common psychological issues were not addressed within the treatment due to their complexity (i.e., eating disorders and substance use disorder). Further limitations concern the assessment phase and the fully automated nature of the treatment. Indeed, only self-report questionnaires are used to identify possible psychological issues and assign modules during the assessment phase. Although this simplifies the procedure, it also makes it more challenging to provide an in-depth assessment. Lastly, the user's complete autonomy does not make possible to verify whether theoretical sessions of psychoeducation and exercises have been completed.

\section{Conclusions}

The MindBlooming project is a straightforward attempt to respond to the rising levels of psychological distress among college students by providing a readily accessible and always-available treatment. Similar studies have been conducted or are planned to be 
performed worldwide and became even more essential after the COVID-19 pandemic, but, to the best of our knowledge, this is the first study in Italy with these characteristics (i.e., a multi-approach IBI that deals with different psychological and physical problems, and is personalized). Hopefully, we assume that the results of our study will contribute to the growing research on Internet-delivered treatments. If the expected results are obtained, MindBlooming could contribute to: (a) the development of more adequate treatments for low- to moderate-intensity mental health symptomatology, tailored to individual needs and targeting specific symptoms; (b) the improvement of the quality of life of university students; and (c) the consistent reduction of mental health care system costs. MindBlooming is easily scalable, allowing it to also be implemented in different contexts and populations (e.g., university workers, people with mental disorders, and adolescents).

Supplementary Materials: The following supporting information can be downloaded at: https: / / www.mdpi.com/article/10.3390/ijerph19052711/s1, Figure S1: Study design and assessments; Figure S2: Detailed screening in the two arms of the study.

Author Contributions: Conceptualization, E.P., D.M. and R.C.; methodology, M.D.F., F.T., G.B., I.D.F., D.G., K.P.L., L.P., A.P., G.S., M.M., J.L.-C., D.R., A.G., E.P., D.M. and R.C.; writing-original draft preparation, M.D.F. and F.T.; writing-review and editing, all the co-authors; supervision, E.P., D.M. and R.C.; project administration, R.C. All authors have read and agreed to the published version of the manuscript.

Funding: This research received no external funding.

Institutional Review Board Statement: The study was conducted according to the guidelines of the Declaration of Helsinki and approved by the Ethics Committee of the University of Milano-Bicocca (protocol code 0018862/21; 16 February 2021).

Informed Consent Statement: Informed consent will be obtained from all subjects involved in the study.

Conflicts of Interest: The authors declare no conflict of interest.

\section{References}

1. Di Consiglio, M.; Merola, S.; Pascucci, T.; Violani, C.; Couyoumdjian, A. The Impact of COVID-19 Pandemic on Italian University Students' Mental Health: Changes across the Waves. Int. J. Environ. Res. Public Health 2021, 18, 9897. [CrossRef] [PubMed]

2. Herrero, R.; Mira, A.; Cormo, G.; Etchemendy, E.; Baños, R.; García-Palacios, A.; Ebert, D.D.; Franke, M.; Berger, T.; Schaub, M.P.; et al. An Internet Based Intervention for Improving Resilience and Coping Strategies in University Students: Study Protocol for a Randomized Controlled Trial. Internet Interv. 2019, 16, 43-51. [CrossRef] [PubMed]

3. Adamo, S.; Irene, S.; Emanuele, P.; Rosaria, F.M.; Antonio, P. Brief Psychodynamic Counselling in a University Setting. Procedia-Soc. Behav. Sci. 2010, 5, 1151-1159.

4. Auerbach, R.P.; Mortier, P.; Bruffaerts, R.; Alonso, J.; Benjet, C.; Cuijpers, P.; Demyttenaere, K.; Ebert, D.D.; Green, J.G.; Hasking, P.; et al. WHO World Mental Health Surveys International College Student Project: Prevalence and Distribution of Mental Disorders. J. Abnorm. Psychol. 2018, 127, 623. [CrossRef] [PubMed]

5. Oswalt, S.B.; Lederer, A.M.; Chestnut-Steich, K.; Day, C.; Halbritter, A.; Ortiz, D. Trends in College Students' Mental Health Diagnoses and Utilization of Services, 2009-2015. J. Am. Coll. Health 2020, 68, 41-51. [CrossRef]

6. Mortier, P.; Cuijpers, P.; Kiekens, G.; Auerbach, R.P.; Demyttenaere, K.; Green, J.G.; Kessler, R.C.; Nock, M.K.; Bruffaerts, R. The Prevalence of Suicidal Thoughts and Behaviours among College Students: A Meta-Analysis. Psychol. Med. 2018, 48, 554-565. [CrossRef]

7. Rosales-Ricardo, Y.; Rizzo-Chunga, F.; Mocha-Bonilla, J.; Ferreira, J.P. Prevalence of Burnout Syndrome in University Students: A Systematic Review. Salud Ment. 2021, 44, 91-102. [CrossRef]

8. Sivertsen, B.; Råkil, H.; Munkvik, E.; Lønning, K.J. Cohort Profile: The SHoT-Study, a National Health and Well-Being Survey of Norwegian University Students. BMJ Open 2019, 9, e025200. [CrossRef]

9. Storrie, K.; Ahern, K.; Tuckett, A. A Systematic Review: Students with Mental Health Problems-A Growing Problem. Int. J. Nurs. Pract. 2010, 16, 1-6. [CrossRef]

10. Gross, J.J. Emotion Regulation: Affective, Cognitive, and Social Consequences. Psychophysiology 2002, 39, 281-291. [CrossRef]

11. Cacioppo, J.T.; Hawkley, L.C. Social Isolation and Health, with an Emphasis on Underlying Mechanisms. Perspect. Biol. Med. 2003, 46, S39-S52. [CrossRef] [PubMed] 
12. Park, C.; Majeed, A.; Gill, H.; Tamura, J.; Ho, R.C.; Mansur, R.B.; Nasri, F.; Lee, Y.; Rosenblat, J.D.; Wong, E.; et al. The Effect of Loneliness on Distinct Health Outcomes: A Comprehensive Review and Meta-Analysis. Psychiatry Res. 2020, $294,113514$. [CrossRef] [PubMed]

13. Cludius, B.; Mennin, D.; Ehring, T. Emotion Regulation as a Transdiagnostic Process. Emotion 2020, 20, 37. [CrossRef] [PubMed]

14. Ishii, T.; Tachikawa, H.; Shiratori, Y.; Hori, T.; Aiba, M.; Kuga, K.; Arai, T. What Kinds of Factors Affect the Academic Outcomes of University Students with Mental Disorders? A Retrospective Study Based on Medical Records. Asian J. Psychiatry 2018, $32,67-72$. [CrossRef] [PubMed]

15. Ebert, D.D.; Harrer, M.; Apolinário-Hagen, J.; Baumeister, H. Digital Interventions for Mental Disorders: Key Features, Efficacy, and Potential for Artificial Intelligence Applications. In Frontiers in Psychiatry; Springer: Singapore, 2019 ; pp. $583-627$.

16. Franzoi, I.G.; D'Ovidio, F.; Costa, G.; d'Errico, A.; Granieri, A. Self-Rated Health and Psychological Distress among Emerging Adults in Italy: A Comparison between Data on University Students, Young Workers and Working Students Collected through the 2005 and 2013 National Health Surveys. Int. J. Environ. Res. Public Health 2021, 18, 6403. [CrossRef]

17. Cuijpers, P.; Kleiboer, A.; Karyotaki, E.; Riper, H. Internet and Mobile Interventions for Depression: Opportunities and Challenges. Depress. Anxiety 2017, 34, 596-602. [CrossRef]

18. Ebert, D.D.; Van Daele, T.; Nordgreen, T.; Karekla, M.; Compare, A.; Zarbo, C.; Brugnera, A.; Øverland, S.; Trebbi, G.; Jensen, K.L.; et al. Internet-and Mobile-Based Psychological Interventions: Applications, Efficacy, and Potential for Improving Mental Health. Eur. Psychol. 2018, 23, 167-187. [CrossRef]

19. Andersson, G.; Cuijpers, P.; Carlbring, P.; Riper, H.; Hedman, E. Guided Internet-based vs. Face-to-face Cognitive Behavior Therapy for Psychiatric and Somatic Disorders: A Systematic Review and Meta-analysis. World Psychiatry 2014, 13, 288-295. [CrossRef]

20. Olthuis, J.V.; Watt, M.C.; Bailey, K.; Hayden, J.A.; Stewart, S.H. Therapist-supported Internet Cognitive Behavioural Therapy for Anxiety Disorders in Adults. Cochrane Database Syst. Rev. 2016, 3, CD011565. [CrossRef]

21. Cuijpers, P.; van Straten, A.; Andersson, G. Internet-Administered Cognitive Behavior Therapy for Health Problems: A Systematic Review. J. Behav. Med. 2008, 31, 169-177. [CrossRef]

22. Baños, R.M.; Etchemendy, E.; Mira, A.; Riva, G.; Gaggioli, A.; Botella, C. Online Positive Interventions to Promote Well-Being and Resilience in the Adolescent Population: A Narrative Review. Front. Psychiatry 2017, 8, 10. [CrossRef] [PubMed]

23. Davies, E.B.; Morriss, R.; Glazebrook, C. Computer-Delivered and Web-Based Interventions to Improve Depression, Anxiety, and Psychological Well-Being of University Students: A Systematic Review and Meta-Analysis. J. Med Internet Res. 2014, 16, e130. [CrossRef]

24. Berrouiguet, S.; Baca-García, E.; Brandt, S.; Walter, M.; Courtet, P. Fundamentals for Future Mobile-Health (MHealth): A Systematic Review of Mobile Phone and Web-Based Text Messaging in Mental Health. J. Med. Internet Res. 2016, 18, e5066. [CrossRef] [PubMed]

25. Harrer, M.; Adam, S.H.; Baumeister, H.; Cuijpers, P.; Karyotaki, E.; Auerbach, R.P.; Kessler, R.C.; Bruffaerts, R.; Berking, M.; Ebert, D.D. Internet Interventions for Mental Health in University Students: A Systematic Review and Meta-Analysis. Int. J. Methods Psychiatr. Res. 2019, 28, e1759. [CrossRef] [PubMed]

26. Kunzler, A.M.; Helmreich, I.; König, J.; Chmitorz, A.; Wessa, M.; Binder, H.; Lieb, K. Psychological Interventions to Foster Resilience in Healthcare Students. Cochrane Database Syst. Rev. 2020, 7, CD013684. [CrossRef] [PubMed]

27. Chandrashekar, P. Do Mental Health Mobile Apps Work: Evidence and Recommendations for Designing High-Efficacy Mental Health Mobile Apps. Mhealth 2018, 4, 6. [CrossRef]

28. Wilks, C.R.; Lungu, A.; Ang, S.Y.; Matsumiya, B.; Yin, Q.; Linehan, M.M. A Randomized Controlled Trial of an Internet Delivered Dialectical Behavior Therapy Skills Training for Suicidal and Heavy Episodic Drinkers. J. Affect. Disord. 2018, 232, 219-228. [CrossRef]

29. Griffiths, K.M.; Christensen, H. Review of Randomised Controlled Trials of Internet Interventions for Mental Disorders and Related Conditions. Clin. Psychol. 2006, 10, 16-29. [CrossRef]

30. Design. Available online: https:/ / material.io/design (accessed on 10 September 2021).

31. Larsen, D.L.; Attkisson, C.C.; Hargreaves, W.A.; Nguyen, T.D. Assessment of Client/Patient Satisfaction: Development of a General Scale. Eval. Program Plan. 1979, 2, 197-207. [CrossRef]

32. Olié, E.; Guillaume, S.; Jaussent, I.; Courtet, P.; Jollant, F. Higher Psychological Pain during a Major Depressive Episode May Be a Factor of Vulnerability to Suicidal Ideation and Act. J. Affect. Disord. 2010, 120, 226-230. [CrossRef]

33. Brooke, J. SUS-A Quick and Dirty Usability Scale. Usability Eval. Ind. 1996, 189, 4-7.

34. Schulz, K.F.; Altman, D.G.; Moher, D.; The CONSORT Group. CONSORT 2010 Statement: Updated Guidelines for Reporting Parallel Group Randomised Trials. BMC Med. 2010, 8, 18. [CrossRef] [PubMed]

35. Beck, A.T. Thinking and Depression: II. Theory and Therapy. Arch. Gen. Psychiatry 1964, 10, 561-571. [CrossRef] [PubMed]

36. Hayes, S.C.; Strosahl, K.D.; Wilson, K.G. Acceptance and Commitment Therapy: The Process and Practice of Mindful Change; Guilford Press: New York, NY, USA, 2011; ISBN 1-60918-962-0.

37. Segal, Z.V.; Williams, J.M.G.; Teasdale, J.D. Mindfulness-Based Cognitive Therapy for Depression: A New Approach to Preventing Relapse; Guilford Press: New York, NY, USA, 2002.

38. Irving, J.A.; Segal, Z.V. Mindfulness-Based Cognitive Therapy: Current Status and Future Applications. Sante Ment. Que. 2013, 38, 65-82. [CrossRef] 
39. Kabat-Zinn, J. An Outpatient Program in Behavioral Medicine for Chronic Pain Patients Based on the Practice of Mindfulness Meditation: Theoretical Considerations and Preliminary Results. Gen. Hosp. Psychiatry 1982, 4, 33-47. [CrossRef]

40. Linehan, M. Skills Training Manual for Treating Borderline Personality Disorder; Guilford Press: New York, NY, USA, 1993; Volume 29.

41. Taskforce, A.P. Evidence Based Practice in Psychology: APA Presidential Taskforce on Evidence Based Practice. Am. Psychol. 2006, $61,271-285$.

42. Klerman, G.L.; Weissman, M.M. Interpersonal Psychotherapy of Depression: A Brief, Focused, Specific Strategy; Jason Aronson, Incorporated: Lanham, MD, USA, 1994; ISBN 1-4616-2900-4.

43. Beck, J.S. Cognitive Behavior Therapy: Basics and Beyond; The Guilford Press: New York, NY, USA, 2011 ; ISBN 1609185048.

44. Simos, G.; Hofmann, S.G. CBT for Anxiety Disorders: A Practitioner Book; John Wiley \& Sons: Hoboken, NJ, USA, 2013; ISBN 1-118-31676-2.

45. Morin, C.M.; Bootzin, R.R.; Buysse, D.J.; Edinger, J.D.; Espie, C.A.; Lichstein, K.L. Psychological and Behavioral Treatment of Insomnia: Update of the Recent Evidence (1998-2004). Sleep 2006, 29, 1398-1414. [CrossRef]

46. Sharma, M.P.; Andrade, C. Behavioral Interventions for Insomnia: Theory and Practice. Indian J. Psychiatry 2012, $54,359$. [CrossRef]

47. Hoffman, J.E.; Taylor, K.; Manber, R.; Trockel, M.; Gehrman, P.; Woodward, S.; Ruzek, J.I. CBT-i Coach; Version 1.0; Mobile Application Software; US Department of Veterans Affairs: Washington, DC, USA, 2013.

48. Edinger, J.D.; Carney, C.E. Overcoming Insomnia: A Cognitive-Behavioral Therapy Approach, Therapist Guide; Oxford University Press: Oxford, UK, 2014; ISBN 0-19-933939-2.

49. Jacobson, E. Progressive Relaxation; Midway Reprint; The University of Chicago Press: Chicago, IL, USA, 1974.

50. Lichstein, K.L.; Riedel, B.W.; Wilson, N.M.; Lester, K.W.; Aguillard, R.N. Relaxation and Sleep Compression for Late-Life Insomnia: A Placebo-Controlled Trial. J. Consult. Clin. Psychol. 2001, 69, 227. [CrossRef]

51. Bryan, C.J.; Rudd, M.D. Brief Cognitive-Behavioral Therapy for Suicide Prevention; Guilford Publications: New York, NY, USA, 2018; ISBN 1-4625-3666-2.

52. Bryan, C.J. Cognitive Behavioral Therapy for Suicide Prevention (CBT-SP): Implications for Meeting Standard of Care Expectations with Suicidal Patients. Behav. Sci. Law 2019, 37, 247-258. [CrossRef]

53. Stanley, B.; Brown, G.; Brent, D.A.; Wells, K.; Poling, K.; Curry, J.; Kennard, B.D.; Wagner, A.; Cwik, M.F.; Klomek, A.B.; et al. Cognitive-Behavioral Therapy for Suicide Prevention (CBT-SP): Treatment Model, Feasibility, and Acceptability. J. Am. Acad. Child Adolesc. Psychiatry 2009, 48, 1005-1013. [CrossRef] [PubMed]

54. DeCou, C.R.; Comtois, K.A.; Landes, S.J. Dialectical Behavior Therapy Is Effective for the Treatment of Suicidal Behavior: A Meta-Analysis. Behav. Ther. 2019, 50, 60-72. [CrossRef] [PubMed]

55. Linehan, M.M.; Korslund, K.E.; Harned, M.S.; Gallop, R.J.; Lungu, A.; Neacsiu, A.D.; McDavid, J.; Comtois, K.A.; Murray-Gregory, A.M. Dialectical Behavior Therapy for High Suicide Risk in Individuals with Borderline Personality Disorder: A Randomized Clinical Trial and Component Analysis. JAMA Psychiatry 2015, 72, 475-482. [CrossRef] [PubMed]

56. International Association for Suicide Prevention (ICSPRC). Advice on Questions/Survey Tools Relevant to Suicide Prevention Research in Relation to COVID-19. Available online: https://iasp.info/wp-content/uploads/ICSPRC_COVID_advice_on_ questions.pdf (accessed on 5 March 2021).

57. Williams Institute Data Collection Archives. Available online: https://williamsinstitute.law.ucla.edu/issues/data-collection/ (accessed on 5 March 2021).

58. Beck, A.T.; Steer, R.A.; Brown, G.K. Beck Depression Inventory (BDI-II); Pearson: London, UK, 1996; Volume 10.

59. Ghisi, M.; Flebus, G.B.; Montano, A.; Sanavio, E.; Sica, C. Manuale BDI-II. Beck Depression Inventory-II; Organizzazioni Speciali, Adattamento Italiano: Firenze, Italy, 2006.

60. Pedrabissi, L.; Santinello, M. Verifica Della Validità Dello STAI Forma Y Di Spielberger. Giunti Organizzazioni Speciali 1989, 191-192, 11-14.

61. Spielberger, C.D. State-Trait Anxiety Inventory for Adults; Consulting Psychologists Press: Palo Alto, CA, USA, 1983.

62. Buysse, D.J.; Reynolds, C.F., III; Monk, T.H.; Berman, S.R.; Kupfer, D.J. The Pittsburgh Sleep Quality Index: A New Instrument for Psychiatric Practice and Research. Psychiatry Res. 1989, 28, 193-213. [CrossRef]

63. Curcio, G.; Tempesta, D.; Scarlata, S.; Marzano, C.; Moroni, F.; Rossini, P.M.; Ferrara, M.; De Gennaro, L. Validity of the Italian Version of the Pittsburgh Sleep Quality Index (PSQI). Neurol. Sci. 2013, 34, 511-519. [CrossRef]

64. Posner, K.; Brown, G.K.; Stanley, B.; Brent, D.A.; Yershova, K.V.; Oquendo, M.A.; Currier, G.W.; Melvin, G.A.; Greenhill, L.; Shen S. The Columbia-Suicide Severity Rating Scale: Initial Validity and Internal Consistency Findings from Three Multisite Studies with Adolescents and Adults. Am. J. Psychiatry 2011, 168, 1266-1277. [CrossRef]

65. Fiorilli, C.; Galimberti, V.; De Stasio, S.; Di Chiacchio, C.; Albanese, O. L'utilizzazione Dello School Burnout Inventory (SBI) Con Studenti Italiani Di Scuola Superiore Di Primo e Secondo Grado. Psicol. Clin. Svilupp. 2014, 18, 403-424.

66. Salmela-Aro, K.; Kiuru, N.; Leskinen, E.; Nurmi, J.-E. School Burnout Inventory (SBI) Reliability and Validity. Eur. J. Psychol. Assess. 2009, 25, 48-57. [CrossRef]

67. Gratz, K.L.; Roemer, L. Multidimensional Assessment of Emotion Regulation and Dysregulation: Development, Factor Structure, and Initial Validation of the Difficulties in Emotion Regulation Scale. J. Psychopathol. Behav. Assess. 2004, 26, 41-54. [CrossRef]

68. Lausi, G.; Quaglieri, A.; Burrai, J.; Mari, E.; Giannini, A.M. Development of the DERS-20 among the Italian Population: A Study for a Short Form of the Difficulties in Emotion Regulation Scale. Mediterr. J. Clin. Psychol. 2020, 8. [CrossRef] 
69. Davis, M.H. A Multidimensional Approach to Individual Differences in Empathy; The University of Texas: Austin, TX, USA, 1980.

70. Ingoglia, S.; Lo Coco, A.; Albiero, P. Development of a Brief Form of the Interpersonal Reactivity Index (B-IRI). J. Personal. Assess. 2016, 98, 461-471. [CrossRef] [PubMed]

71. Caraceni, A.; Mendoza, T.R.; Mencaglia, E.; Baratella, C.; Edwards, K.; Forjaz, M.J.; Martini, C.; Serlin, R.C.; de Conno, F.; Cleeland, C.S. A Validation Study of an Italian Version of the Brief Pain Inventory (Breve Questionario per La Valutazione Del Dolore). Pain 1996, 65, 87-92. [CrossRef]

72. Cleeland, C.S.; Ryan, K. The Brief Pain Inventory; The University of Texas MD Anderson Cancer Center, Pain Research Group: Houston, TX, USA, 1991; Volumes 143-147.

73. WHOQOL Group. Development of the World Health Organization WHOQOL-BREF Quality of Life Assessment. Psychol. Med. 1998, 28, 551-558. [CrossRef] [PubMed]

74. Castronovo, V.; Galbiati, A.; Marelli, S.; Brombin, C.; Cugnata, F.; Giarolli, L.; Anelli, M.M.; Rinaldi, F.; Ferini-Strambi, L. Validation Study of the Italian Version of the Insomnia Severity Index (ISI). Neurol. Sci. 2016, 37, 1517-1524. [CrossRef] [PubMed]

75. Bagby, R.M.; Parker, J.D.; Taylor, G.J. The Twenty-Item Toronto Alexithymia Scale-I: Item Selection and Cross-Validation of the Factor Structure. J. Psychosom. Res. 1994, 38, 23-32. [CrossRef]

76. Bressi, C.; Taylor, G.; Parker, J.; Bressi, S.; Brambilla, V.; Aguglia, E.; Allegranti, I.; Bongiorno, A.; Giberti, F.; Bucca, M.; et al. Cross Validation of the Factor Structure of the 20-Item Toronto Alexithymia Scale: An Italian Multicenter Study. J. Psychosom. Res. 1996, 41, 551-559. [CrossRef]

77. Carver, C.S.; Scheier, M.F.; Weintraub, J.K. Assessing Coping Strategies: A Theoretically Based Approach. J. Personal. Soc. Psychol. 1989, 56, 267. [CrossRef]

78. Foà, C.; Tonarelli, A.; Caricati, L.; Fruggeri, L. COPE-NVI-25: Validazione Italiana Della Versione Ridotta Della Coping Orientation to the Problems Experienced (COPE-NVI). Psicol. Salut. 2015, 123-140. [CrossRef]

79. Gray, M.J.; Litz, B.T.; Hsu, J.L.; Lombardo, T.W. Psychometric Properties of the Life Events Checklist. Assessment 2004, 11, 330-341. [CrossRef]

80. Linehan, M.M.; Goodstein, J.L.; Nielsen, S.L.; Chiles, J.A. Reasons for Staying Alive When You Are Thinking of Killing Yourself: The Reasons for Living Inventory. J. Consult. Clin. Psychol. 1983, 51, 276. [CrossRef] [PubMed]

81. Heber, E.; Ebert, D.D.; Lehr, D.; Cuijpers, P.; Berking, M.; Nobis, S.; Riper, H. The Benefit of Web-and Computer-Based Interventions for Stress: A Systematic Review and Meta-Analysis. J. Med. Internet Res. 2017, 19, e32. [CrossRef] [PubMed]

82. Schönbrodt, F.D.; Wagenmakers, E.-J. Bayes Factor Design Analysis: Planning for Compelling Evidence. Psychon. Bull. Rev. 2018, 25, 128-142. [CrossRef] [PubMed]

83. Rouder, J.N.; Speckman, P.L.; Sun, D.; Morey, R.D.; Iverson, G. Bayesian t Tests for Accepting and Rejecting the Null Hypothesis. Psychon. Bull. Rev. 2009, 16, 225-237. [CrossRef] [PubMed]

84. Rouder, J.N.; Morey, R.D.; Speckman, P.L.; Province, J.M. Default Bayes Factors for ANOVA Designs. J. Math. Psychol. 2012, 56, 356-374. [CrossRef]

85. Copay, A.G.; Subach, B.R.; Glassman, S.D.; Polly Jr, D.W.; Schuler, T.C. Understanding the Minimum Clinically Important Difference: A Review of Concepts and Methods. Spine J. 2007, 7, 541-546. [CrossRef]

86. James, G.; Witten, D.; Hastie, T.; Tibshirani, R. An Introduction to Statistical Learning; Springer: Cham, Switzerland, 2013; Volume 112. 